\title{
Sandwich Osteotomy With Interposition Of A Bovine Block Bone Graft for Vertical Ridge Augmentation
}

\author{
Osteotomía en Sandwich con Interposición de Injerto Óseo \\ Bovino en Bloque para Aumento Vertical de Reborde
}

\author{
Claudio Ferreira Nóia*,**; Rafael Ortega-Lopes**; Bruno Costa Martins de Sá**; Claudinei \\ Ferreira Nóia**; Fábio Augusto Coelho de Oliveira** \& Sergio Olate****,****
}

NÓIA, C. F.; ORTEGA-LOPES, R.; DE SÁ, B. C. M.; NÓIA, C. F.; DE OLIVEIRA, F. A. C. \& OLATE, S. Sandwich osteotomy with interposition of a bovine block bone graft for vertical ridge augmentation. Int. $J$. Med. Surg. Sci., 2(2):475-479, 2015.

SUMMARY: The aim of the present study was to report the clinical case of a patient with a vertical defect of the alveolar ridge, which prevented the installation of dental implants without first treating the defect in question. A 32-year old female patient with a height defect of approximately $6 \mathrm{~mm}$ in the region of the missing absent teeth (13 and 14). The patient was treated using the sandwich osteotomy technique, with the interposition of a block bone graft of bovine origin. No complications were reported in the postoperative period. After seven months, two dental implants were installed in the relevant region. The bovine bone graft was incorporated into the relevant area. The bovine bone block graft used in this clinical case was shown to be a viable option for interposition between bone segments that have been osteotomized via sandwich osteotomy.

KEY WORDS: Alveolar ridge augmentation; Bone graft; Dental implants.

\section{INTRODUCTION}

The treatment of vertical bone defects of the alveolar ridge, for the subsequent installation of dental implants, remains a great challenge for dental surgeons today (Nóia et al., 2012; Laviv et al., 2014). According to the literature, the high index of exposure and the nutrition difficulty involved in the use of block bone grafts, or particulate bone grafts, when performed on the alveolar ridge in areas with this type of defect, are factors that directly and negatively affect the results of these types of grafts (Bormann et al., 2011; Tavares et al., 2013).
The technique of segmenting using interpositional bone grafts, or sandwich osteotomy, has become more popular in recent years among surgeons treating this type of condition due to the low level of exposure, a lack of complications, the easy nutrition of the graft and the high percentage of success (Bormann etal.; Laviv et al.; Triaca et al., 2014). Using this technique, it is possible to readjust height defects of between 4 and $8 \mathrm{~mm}$ and to reposition badly-positioned implants, thereby optimizing their long-term function, esthetics and stability (Nóia et al.).

This technique was developed using autografts between the osteotomized segments. The literature currently contains studies that

* Dentistry Department, University of Araras (UNIARARAS/SP), Araras, Brazil.

** Dentistry Department, College Ciodonto, Rondônia, Brazil.

**** Dentistry Department, APCD Piraciaba, Piraciaba, Brazil.

**** Division of Oral and Maxillofacial Surgery, Universidad de La Frontera, Temuco, Chile.

***** Center for Biomedical Research, Universidad Autónoma de Chile, Temuco, Chile. 
used this material safely and successfully (Bormann et al.; Bell, 2013; Tavares et al.; Laviv et al.). However, since the technique leads to a high index of vascularization and predictability, recent studies have sought to use biomaterials as an alternative to bone autografts, without negatively affecting the clinical results (Tavares et al.; Xuan et al., 2014).

Therefore, the aim of the present study was to report a clinical case that treated a vertical defect of the alveolar ridge using sandwich osteotomy and a block bone graft of bovine origin between the osteotomized segments.

\section{CASE REPORT}

A 32-year old female patient with leucoderma sought rehabilitation with implants after complaining of the loss of dental elements for many years, which had negatively affected her in terms of esthetics and chewing capabilities.

A clinical examination revealed the absence of dental elements 13 and 14, keratinized gingiva and a thick gingival phenotype, as well as a gingival height defect in the region (Fig. 1). A tomographic examination revealed a bone deficiency of 6 $\mathrm{mm}$ in height in the region of the missing teeth.

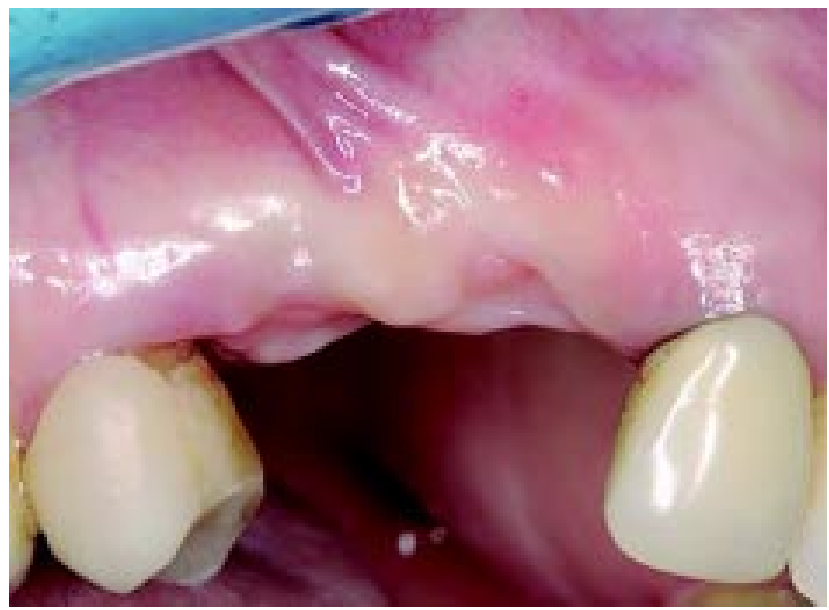

Fig. 1. Initial clinical photograph showing the absence of elements 13 and 14, as well as the thick gingival biotype and the height defect of the gums.
In addition, there was a distance of approximately $20 \mathrm{~mm}$ between the resorbed ridge and the floor of the maxillary sinus and the floor of the nasal cavity (Fig. 2).

The proposed treatment plan involved sandwich osteotomy, with the interposition of a bovine block bone graft, to treat the height defect and enable the future installation of dental implants.

The surgery began by anesthetically blocking the anterior and middle superior

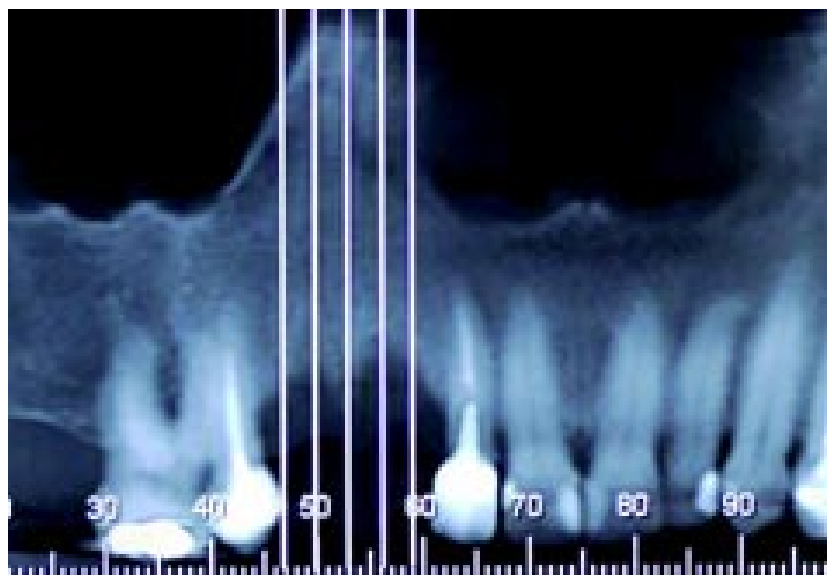

Fig. 2. Tomographic image showing the bone loss at a height of approximately $6 \mathrm{~mm}$.

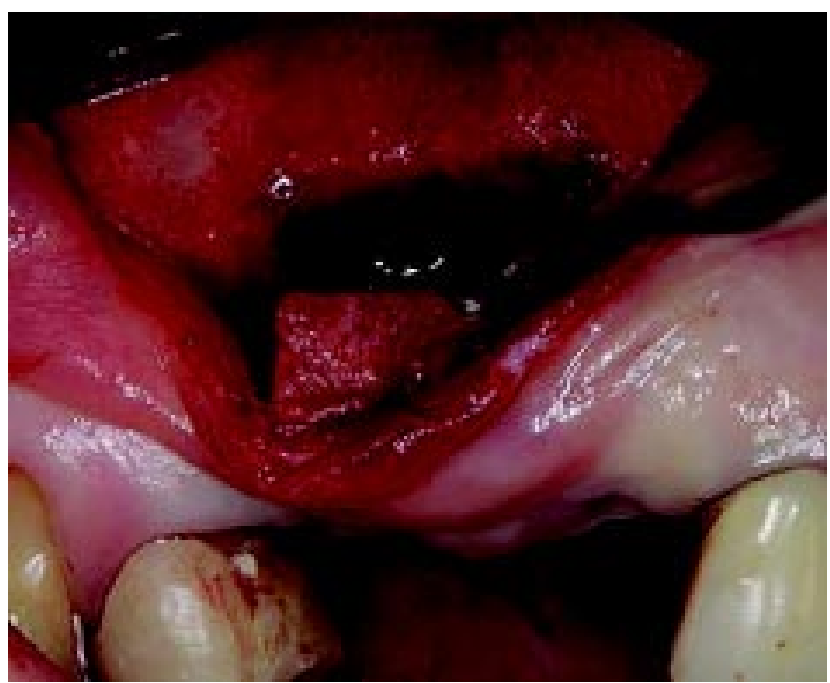

Fig. 3. After incision and mucoperiosteal displacement, vertical and horizontal osteotomies were designed to enable the mobilization of the bone segment in the occlusal direction. This was done in order to correct the height defect, as well as to create space for the interposition of the bovine block bone graft. 
alveolar nerves, as well as the nasopalatine nerve and the greater palatine nerve, with articaine $4 \%$ solution at $1: 100.000$ (Dfl, Rio de Janeiro-Brazil). This was followed by a linear incision $3 \mathrm{~mm}$ above the mucogingival junction. The next step involved mucoperiosteal displacement and the design of the vertical and horizontal osteotomies, using sagittal saws. The final design of the osteotomies, as well as the mobilization of the bone segment, was performed with chisels, taking care not to lacerate the palatal mucosa (Fig. 3).

Subsequently, the bovine block bone graft (Lumina-Bloco, Critéria, São Carlos-Brazil) was prepared and placed in the space created by the mobilization of the bone segment. It was then completely fixed with a plate and $1.5 \mathrm{~mm}$ screws (Engimplan, Rio Claro-Brazil). Special care must be taken with bovine block bone grafts, as they tend to crumble at the time of interposition (Figs. 4 and 5).

A membrane of absorbable collagen was placed over the grafted region (Lumina-Coat, Critéria, São Carlos-Brazil). The procedure was finished with catgut continuous suture and absorbable wire 3-0 (Point-suture, FortalezaBrazil). The patients provisionary prosthesis was adapted so that it would not pressurize the reconstructed area (Fig. 6).

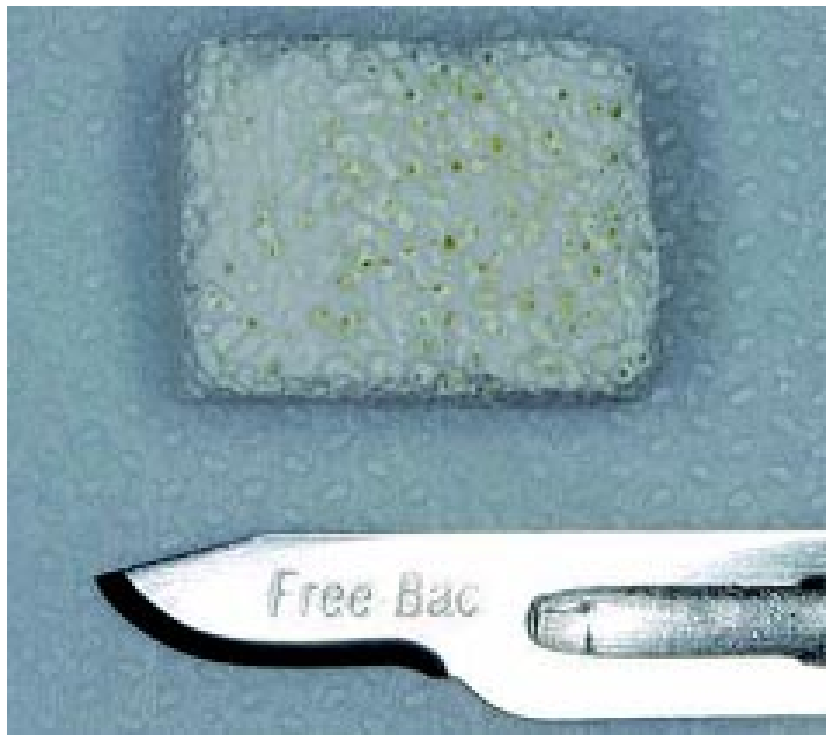

Fig. 4. Bovine block bone graft prepared for interposition.
Seven months after the graft, the patient was reassessed prior to the installation of the dental implants. After careful mucoperiosteal displacement, the fixation system was removed and the incorporation of the bovine block bone graft was confirmed, with a considerable gain in height correcting the pre-existing defect (Fig. 7). The next step involved the milling and installation of two dental implants (Conexão, São Paulo-Brazil), in accordance with the surgical guide and the reverse planning carried out (Fig. 8).

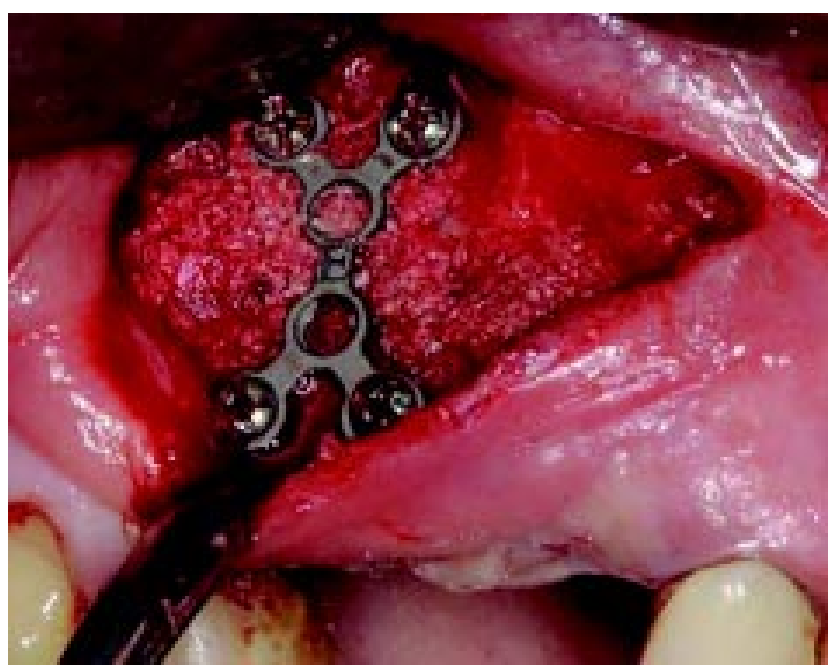

Fig. 5. Bovine block bone graft in position and the segment fixed with a plate and screws. Note that the block tends to fragment during the act of interposition.

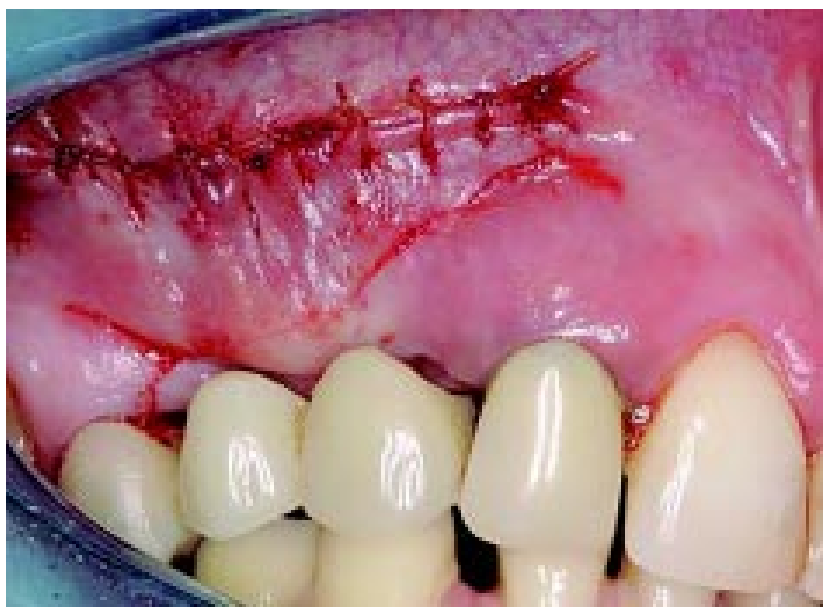

Fig. 6. Performance of catgut absorbable suture. Note the adaptation (stretch) of the mucous due to the correction of the height defect. Another significant factor is the adaptation of the provisionary prosthesis of the patient, without putting pressure on the graft region. 


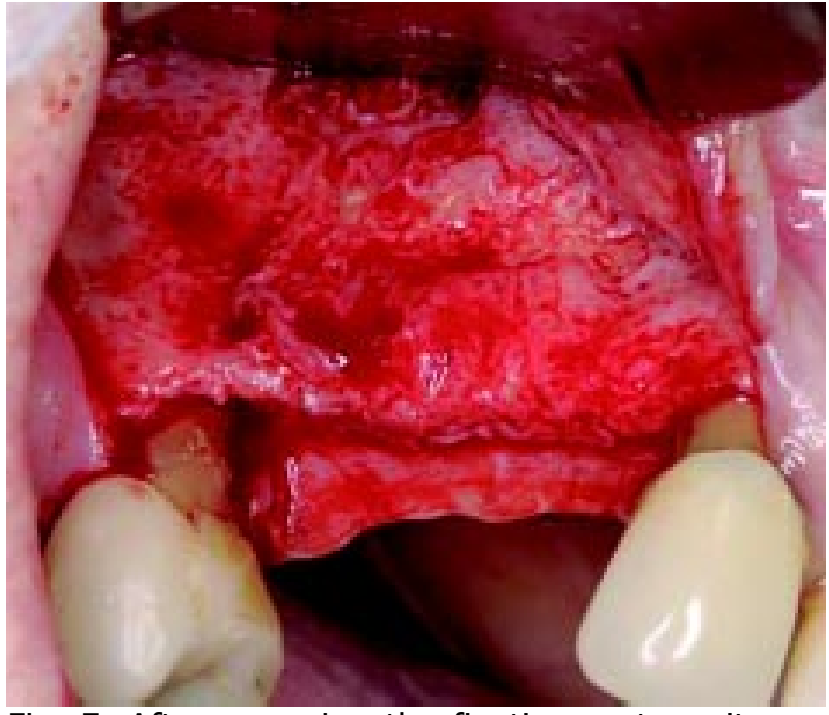

Fig. 7. After removing the fixation system, it was possible to visualize the excellent incorporation of the bovine block bone graft, as well as the correction of the bone height defect.

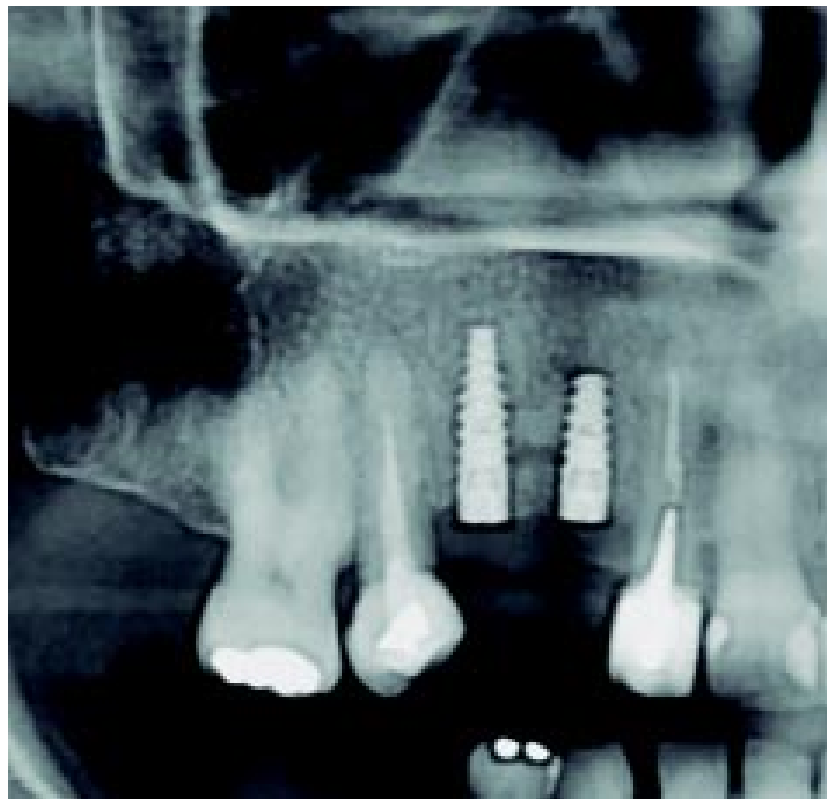

Fig. 8. Panoramic radiography providing a partial view of the implants installed.

\section{DISCUSSION}

Nowadays, patients who seek treatment involving dental implants usually wish to restore their masticatory function, comfort, esthetics and phonetics, regardless of the existence of atrophy, disease or injuries of the stomatognathic system. In this context, sand- wich osteotomy has been shown to be viable and predictable in the treatment of vertical defects of the alveolar ridge (Bormann et al.; Laviv et al.).

According to the literature, this technique is indicated for the correction of vertical defects located in the anterior region of the jaw and mandible, as well as the posterior region of the mandible (Laviv et al.; Triaca et al.). Maxillary sinus pneumatization usually occurs in the posterior region of the jaw, which leads to the contraindication of this technique, as it favors the elevation of the maxillary sinus floor.

However, Nóia et al. reported a case in which this technique was used in the posterior region of the jaw (dental elements 14, 15 and 16). According to the authors, a loss of bone height, starting from the crest of the alveolar ridge, was recorded, without maxillary sinus pneumatization. In the clinical case presented in this study, the procedure was conducted in the area between the anterior and posterior regions of the jaw (elements 13 and 14), without pneumatization of the maxillary sinus or nasal cavity, both of which would have prevented the procedure from going ahead.

Studies published in the literature on the use of the sandwich osteotomy technique routinely use bone autografts between the osteotomized segments (Bormann et al.; Nóia et al.; Bell et al.; Tavares et al.). However, these same studies state that this technique exhibits a high level of predictability in the results as a result of the continuous contact between the graft and a four-wall defect, which strongly favors its nutrition and a considerably lower degree of reabsorption.

In the clinical case presented in this study, bovine block bone grafts were used between the osteotomized segments and provided a clinically satisfactory result after seven months, favoring a vertical gain of approximately $6 \mathrm{~mm}$, as well as the installation of two dental implants in the region. No similar report has been found in the literature.

Another important factor to be discussed is related to the fact that the authors of previous studies involving the interposition of autografts 
NóiA, C. F.; ORTEGA-LOPES, R.; DE SÁ, B. C. M.; NóIA, C. F.; DE OLIVEIRA, F. A. C. \& OLATE, S. Sandwich osteotomy with interposition of a bovine block bone graft for vertical ridge augmentation. Int. J. Med. Surg. Sci., 2(2):475-479, 2015.

between osteotomized segments recommended the installation of implants four or five months after reconstructive surgery, stating that this time period was sufficient for bone incorporation and neoformation of segments (Bormann et al.; Nóia et al.; Bell et al.; Tavares et al.; Felice et al., 2014). In this clinical case, which used bovine grafts, we decided to allow a period of seven months to pass before installing the implants. This is due to the fact that this modality of graft does not exhibit the same properties or capacity as autografts. Thus, the process of bone incorporation and neoformation with bovine grafts is slower.

\section{CONCLUSION}

The results suggest that bovine block bone grafts were used between the osteotomized segments and provided a clinically satisfactory result. Further studies are required to determine whether this treatment leads to predictably results.

NÓIA, C. F.; ORTEGA-LOPES, R.; DE SÁ, B. C. M.; NÓIA, C. F.; DE OLIVEIRA, F. A. C. \& OLATE, S. Osteotomía en Sandwich con Interposición de Injerto Óseo Bovino en Bloque para Aumento Vertical de Reborde. Int. J. Med. Surg. Sci, 2(2):475-479, 2015.

RESUMEN: El objetivo del estudio fue reportar un caso clínico de un paciente con defecto vertical del reborde alveolar, el cual impedía la instalación de implante dental sin tratar el defecto. Un paciente de 32 años de edad se presentó con un defecto en altura de $6 \mathrm{~mm}$ aproximadamente en el sector de dientes 13 y 14 . EL paciente se trató utilizando un bloque de hueso bovino en una técnica de osteotomía con injerto interposicional. No se observaron complicaciones en el periodo postoperatorio; después de siete meses, dos implantes dentales fueron instalados en la región y clínicamente se observó la incorporación del material de injerto. Se puede concluir que el uso de injerto óseo en bloque de origen bovino puede ser aplicado en esta técnica.

PALABRAS CLAVE: Aumento de reborde alveolar; Injerto óseo; Implante dental.

\section{REFERENCES}

Bell, R. E. Palatal Approach to the Anterior Maxillary Sandwich Osteotomy. J. Oral Maxillofac. Surg., 71:1005-9, 2013.

Bormann, K. H.; Suarez-Cunqueiro, M. M.; Von See, C.; Travassol, F.; Dissmann, J. P.; Ruecker, M. \& Kokemueller, H. \& Gellrich, N. C. Forty Sandwich Osteotomies in Atrophic Mandibles: A Retrospective Study. J. Oral Maxillofac. Surg., 69:1562-70, 2011.

Felice, P.; Barausse, C.; Pistilli, R.; Spinato, S. \& Bernardello, F. Guided "sandwich" technique: a novel surgical approach for safe osteotomies in the treatment of vertical bone defects in the posterior atrophic mandible: a case report. Implant Dent., 23:738-44, 2014.

Laviv, A.; Jensen, O. T.; Tarazi, E. \& Casap, N. Alveolar Sandwich Osteotomy in Resorbed Alveolar Ridge for Dental Implants: A 4-Year Prospective Study. J. Oral Maxillofac. Surg., 72:292-303, 2014.

Nóia, C. F.; Ortega-Lopes, R.; Mazzonetto, R. \& Chaves Netto, H. D. M. Segmental osteotomy with interpositional bone grafting in the posterior maxillary region. Int. J. Oral Maxillofac. Surg., $41: 1563-5,2012$.
Tavares, R. N.; da Escossia, Jr. J.; Santos, S. E.; \& Ferraro-Bezerra M. Bone graft sandwich osteotomy to correct a malpositioned dental implant. Int. J. Oral Maxillofac. Surg., 42(7):901-3, 2013.

Triaca, A.; Bruscoa, D.; Asperiob, P. \& Guijarro-Martínez. $R$. New perspectives in the treatment of severe mandibular atrophy: "double sandwich" osteotomy. Br. J. Oral Maxillofac. Surg., 52(7):664-6, 2014.

Xuan, F.; Lee, C.U. ; Son, J. S.; Fang, Y.; Jeong, S. M. \& Choi, B. H. Vertical Ridge Augmentation Using Xenogenous Bone Blocks: A Comparison Between the Flap and Tunneling Procedures. J. Oral Maxillofac. Surg., 72(9):1660-70, 2014.

Correspondence to:

Prof. Dr. Claudio Ferreira Nóia

University of Araras (UNIARARAS)

Dentistry Department

Av. Dr. Maximiliano Baruto, 500

Jardim Universitário, Araras

São Paulo - Zip-code: 13607-339

BRAZIL

Email: claudioferreira2004@yahoo.com.br claudionoia@uniararas.br

Received: 16-04-2015

Accepted: 22-06-2015 